\title{
FUZZY LOGIC METHOD FOR PREDICTING THE EFFECT OF MAIN FABRIC PARAMETERS INFLUENCING DRAPE PHENOMENON
}

\author{
Thouraya Hamdi ${ }^{1,2, *}$, Adel Ghith ${ }^{3}$, Faten Fayala ${ }^{2}$ \\ 1 Department of Fashion and Textile Design/ College of Arts and Design/ Princess Nourah bint Abdulrahman University \\ 2 University of Monastir, National Engineering School, Laboratory studies of thermal and energy systems, LR99ES31, 5019, Monastir, Tunisia \\ 3 University of Monastir, National Engineering School, Textile Materials and Processes Research Unit, UR17ES33, 5019, Monastir, Tunisia \\ E-mail: thourayahamdi@yahoo.fr
}

\begin{abstract}
:
The main aspect of this research was to predict the drape parameters and describe clearly the drape phenomenon using fuzzy logic method. Forecasting features allow manufacturers to save time and improve their productivity. The bending rigidity, (in warp, weft, and skew direction), shear rigidity, and weight of fabric samples were used as the key input variables for the model, whereas drape coefficient, drape distance ratio, folds depth index, and node number were used as output/response variables. The results show that changing the values of fabric parameters significantly affected the fabric drape and a representative correlation values were found between the experimental values and those calculated by the fuzzy system.
\end{abstract}

\section{Keywords:}

Fuzzy-C-mean (FCM), fuzzy logic, fabric drape, drape coefficient, node number, drape distance ratio, folds depth index

\section{Introduction}

Textile fabrics are often the final product of the textile process. Their properties must directly meet the user requirements; obviously, the prediction of their properties and their final behavior is very important. The fabrics are complex structures. The structural complexity in conjunction with the materials complexity do not usually permit the development of computeraided engineering tools for the support of the design phase, as it usually is the case in other engineering fields, such as mechanical, structural, naval, electrical, and so on. Therefore, a lot of effort has been given toward the development of computational tools for the prediction of the behavior of the fabrics [1].

Fabric engineering activities are increasingly based on computational models that aim at the prediction of the properties and the performance of the fabrics under consideration [2]. Various computational tools have been used to represent the fabrics in a computational environment and to predict their final properties [3-7]. Among others, finite element method (FEM) analysis has supported mainly the prediction of the behavior of the complex textile structures under mechanical loads. In the case of classification problems, artificial neural networks (ANNs) have proved to be a very efficient tool for the fast and precise solution. ANNs have found an increasing application in the textile field in the classification and in the prediction of properties and optimization problems [8].

The drape is proved to be an important criterion in the selection and development of textiles for clothing. It is based on the physical and mechanical properties of fabrics. In this context, it is necessary to highlight the influence of mechanical properties, such as bending rigidity and shear rigidity. Therefore, the drape depends somehow on the construction parameters and fabric materials $[9,10]$.

Drape has been widely studied in the literature review. The fabric drape has been measured by the F.R.L. Drapemeter according to Chu et al. [11]. They defined a dimensionless value called the drape coefficient (DC). Their work was revised by Cusick [12] who modified the experimental method and used a parallel light source reflecting a circular specimen drape shadow from a hanging disc onto a paper ring. The DC calculation is based at this stage in terms of paper tracing and weighing method. It is defined as the ratio between the draped shadow paper weight and the full specimen paper weight. The DC varies from 0 to 1. It is high on stiff fabrics and low on floppy fabrics. But the hanging area of the samples modifies significantly the value of the DC.

Mooreka and Niwa [13] use the DC to characterize the drape ability of fabrics and investigate the relation between this coefficient and some measured mechanical properties. Residual regression and multiple regression methods have been used to find correlations between DC and bending rigidities and weight per unit area of fabric. Ayada and Niwa [14] found that the mechanical properties of fabric are strongly linked to the fabric drape; they proved that bending, shear, and fabric mass are the most important factors affecting the appearance of the garment.

The concept of deformable models is also used by researchers of the field in the modeling and simulation of the textile fabrics. 
Therefore, the works of Bruniaux et al. $[15,16]$ reflect an interest in simulating the dynamic behavior of textile fabrics. Essentially, they study the influence of weaves, the surface density, and the nature of the yarn on the drape. Keeping with the same focus, we shall quote the paper of Ghith et al. [17] through which the author predicts the DC using the artificial neural network method. He also presents the effect of some fabric properties on DC.

We have used the PCA method [18], which has eliminated the thickness parameters as this variable is not correlated with the drape parameters. On the contrary, this method is mainly descriptive. Again, the links cannot be measured and the variables cannot be classified in terms of importance.

In this paper, the authors present the Fuzzy logic method to predict the drape behavior (DC, node number, DDR, and folds depth index [FDI]) that has not been used in the previous researches from a very limited input data that are obtained easily using basic equipments $\left(B_{\text {skew }}, B_{\text {weft }}, B_{\text {warp }}, G\right.$, and $\left.W\right)$. This method is able to deliver all the outputs by a single calculating system. The desired drape parameter values obtained from the Fuzzy logic method are compared to the experimental data obtained from image analysis.

\section{Experimental}

\subsection{Materials}

Sixty-three woven fabrics with twill and plain weaves are chosen for the preparation of samples in this study. Table 1 shows the maximum, minimum, and average standard deviation of fabric properties and drape parameters used under study. The fabric samples are conditioned in standard atmospheric conditions for at least 24 hours to allow them to attain a stable condition before evaluating the drape. The fabrics are $80 \%$ cotton and $20 \%$ cotton/polyester. The fabric weight is measured using French Standard NFG07-104 [19].

The method of measuring the bending rigidity is presented below.

\subsubsection{Measurement of the bending rigidity}

The method used to measure the bending (flexural) rigidity, $B$, of fabrics in this study is known as Cantilever test, and it is presented in Figure 1. It enables the measurement of the fabric bending rigidity in weft, warp, and skew directions. The test method consists of clamping a horizontal strip of each fabric at one end, slipping and allowing the rest of the strip to hang under its proper weight. When the tip of the strip reaches a plane inclined at $41.5^{\circ}$ below the horizontal, the overhanging length is measured and marked $(L)$.

The bending rigidity is calculated using the following equation:

$$
B(\mathrm{cg} . \mathrm{cm})=0.01 \times \mathrm{W}\left(\frac{\mathrm{g}}{\mathrm{m}^{2}}\right) \times \mathrm{C}^{3}(\mathrm{~cm})
$$

where $C=L / 2$ and $L$ is the bending length in $\mathrm{cm}, W=$ the fabric surface mass in $\mathrm{g} / \mathrm{m}^{2}$, and $B=$ the bending rigidity in $\mathrm{cg} \cdot \mathrm{cm}$.

The above formula is used in the calculation of the bending rigidities $B_{\text {warp }}, B_{\text {weft }}$, and $B_{\text {skew }}$, respectively, in the warp, weft, and skew directions.

\subsubsection{Measurement of the shear rigidity}

Determining the shear rigidity is provided within the FAST system. In fact, the latter is a set of instruments that are made to measure mechanical and dimensional properties of a fabric to objectively quantify the esthetic fabric properties. Therefore,

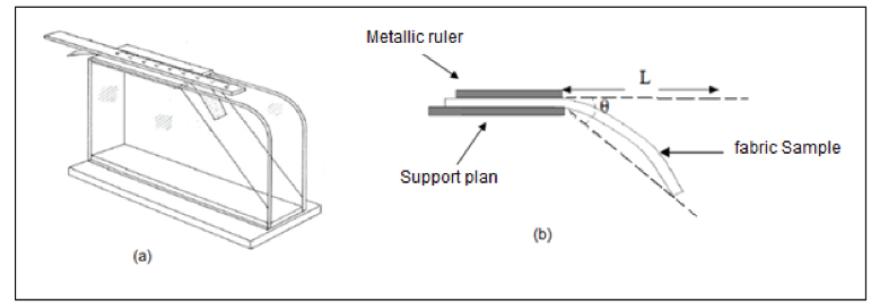

Figure 1.: Experimental device for the fabrics properties

Table 1. Maximum, minimum, and average standard deviation of fabric properties and drape parameters

\begin{tabular}{|c|c|c|c|c|c|c|c|c|c|c|}
\hline Classes & $\begin{array}{c}\text { Statistical } \\
\text { parameters }\end{array}$ & $\begin{array}{c}B_{\text {skew }} \\
(\mathrm{cg} \cdot \mathrm{cm})\end{array}$ & $\begin{array}{c}B_{\text {warp }} \\
(\mathrm{cg} \cdot \mathrm{cm})\end{array}$ & $\begin{array}{c}B_{\text {weft }} \\
(\mathrm{cg} \cdot \mathrm{cm})\end{array}$ & $G(N / m)$ & $W\left(\mathrm{~g} / \mathrm{m}^{2}\right)$ & DC & NN & DDR & FDI \\
\hline \multirow{3}{*}{$\begin{array}{l}\overline{\mathscr{D}} \\
\mathscr{D} \\
\frac{\mathbb{U}}{U}\end{array}$} & Minimum & 0.08 & 0.18 & 0.072 & 30.91 & 65 & 0.28 & 8 & 0.4 & 0.34 \\
\hline & Maximum & 1.42 & 2.48 & 2.22 & 97.62 & 180.56 & 0.55 & 10 & 0.89 & 0.42 \\
\hline & Average & 0.75 & 1.33 & 1.14 & 64.26 & 122.78 & 0.415 & 9 & 0.645 & 0.38 \\
\hline \multirow{3}{*}{$\begin{array}{l}N \\
\mathscr{D} \\
\mathscr{D} \\
\frac{\mathbb{U}}{U}\end{array}$} & Minimum & 0.38 & 2.1 & 1.43 & 51.79 & 130 & 0.53 & 6 & 0.26 & 0.4 \\
\hline & Maximum & 2.7 & 4.5 & 3.5 & 190.6 & 276.4 & 0.78 & 7 & 0.48 & 0.47 \\
\hline & Average & 1.54 & 3.3 & 2.46 & 121.2 & 203.2 & 0.65 & 6.5 & 0.37 & 0.43 \\
\hline \multirow{3}{*}{$\begin{array}{l}m \\
0 \\
0 \\
\mathbb{0} \\
U\end{array}$} & Minimum & 2.3 & 3.9 & 2.9 & 136.6 & 230 & 0.74 & 2 & 0.1 & 0.45 \\
\hline & Maximum & 8.76 & 6.85 & 15.01 & 322.9 & 357 & 0.95 & 5 & 0.28 & 0.56 \\
\hline & Average & 5.53 & 5.37 & 8.95 & 229.7 & 293.5 & 0.84 & 3.5 & 0.19 & 0.50 \\
\hline
\end{tabular}

DC, drape coefficient; NN, node number; DDR, drape distance ratio; FDI, folds depth index. 
in this study, it is necessary to use the FAST-3 system that aims at determining the extension of the fabric under different loads $(5,20$, and $100 \mathrm{gf} / \mathrm{cm})$. This expansion prepares the ground for the measurement of shear stiffness $G$ using the formula given by the following equation:

$$
G\left(\frac{N}{m}\right)=\frac{123}{E_{\text {skew }}(\%)}
$$

G: shear stiffness $(\mathrm{N} / \mathrm{m})$ and $E_{\text {skew }}(\%)$ : extension of the fabric in the skew direction.

\subsubsection{The measurement of DC, NN, FDI, and the DDR}

Modifications in the system of Cusick drapemeter, as shown in Figure 2, are made by the addition of an achievable MATLAB application to calculate the DC (\%) [20].

Image analysis method is used to calculate the real surface of the drape to determine numerical DC. This method is based on the shift from the original color image to the grey level image and finally to the binary one. The method of image processing for the fabric drape measurement is characterized by precision, speed, and the ability to reach various measurements.

The DC can be calculated using the following formula:

$$
\mathrm{DC}=\frac{\text { drape surface }(\text { pixel })-\pi \times(\text { supported disc ray }(\mathrm{cm}) \times c)^{2}}{\pi \times(\text { total ray }(\mathrm{cm}) \times c)^{2}-\pi \times(\text { supported disc ray }(\mathrm{cm}) \times c)^{2}}
$$

where DC is the drape coefficient and $c$ the correlation between the centimeter and the pixel.

The node number is an important parameter linked to the virtual appearance of clothing. The distribution of the different distances of all the points of the outer contour shows the presence of the minimums and the maximums as shown in Figure 3 . The number of nodes is the number of maximums found in the curve representing the ray as a function of the angle of rotation.

The DDR and the FDI are calculated using the equation formula submitted by [21] (Figure 4):

$$
\mathrm{DDR}=\frac{R-r_{\mathrm{ad}}}{R-r}
$$

where $r_{\text {ad }}$ is the rays mean value of fabric drape.

$$
\mathrm{FDI}=\frac{r_{\max }-r_{\min }}{R-r}
$$

where $r_{\max }$ is the maximum ray of draped sample and $r_{\min }$ is the minimum ray of draped sample.

\subsection{Fuzzy logic method}

The concept of Fuzzy logic comes from the observation that the Boolean variable taking only two values: true or false. Thus, several areas own reasoning is applying the Fuzzy logic of modeling, decision support, and the representation of
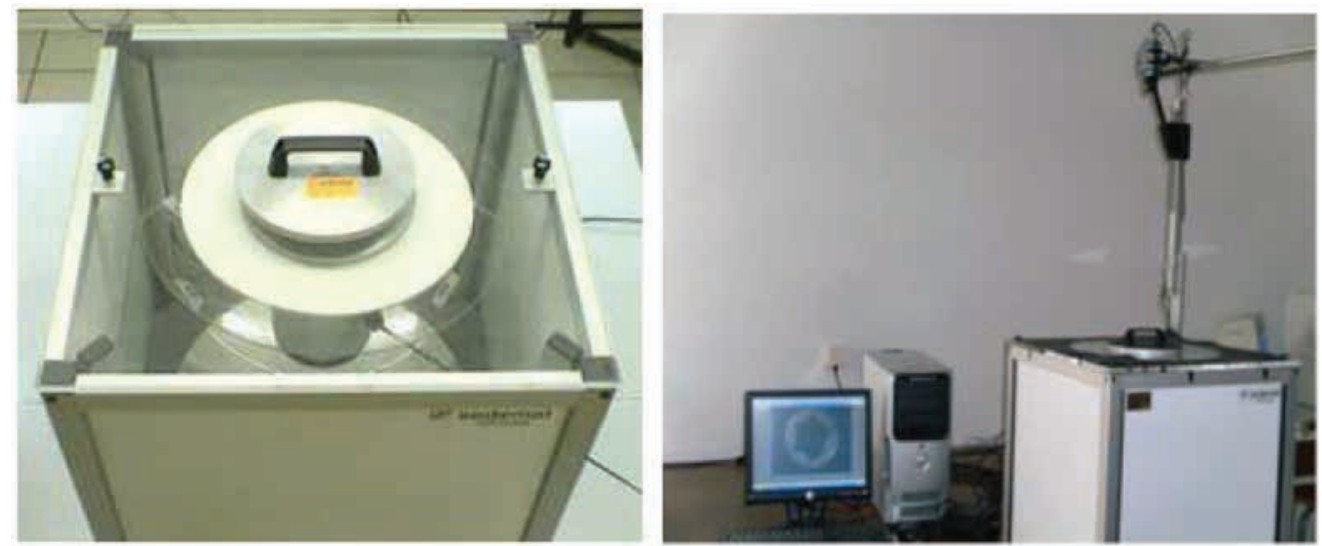

Figure 2. Experimental device for determination of drape parameters
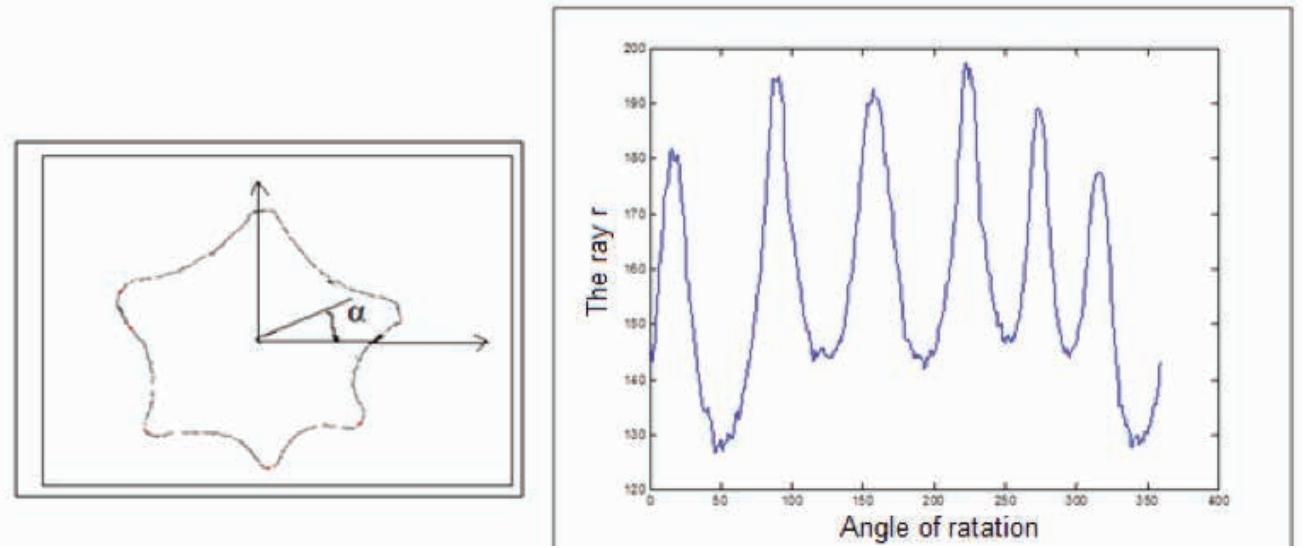

Figure 3. Presentation of the angle of calculation of rays and the distribution of the rays throughout the drape 


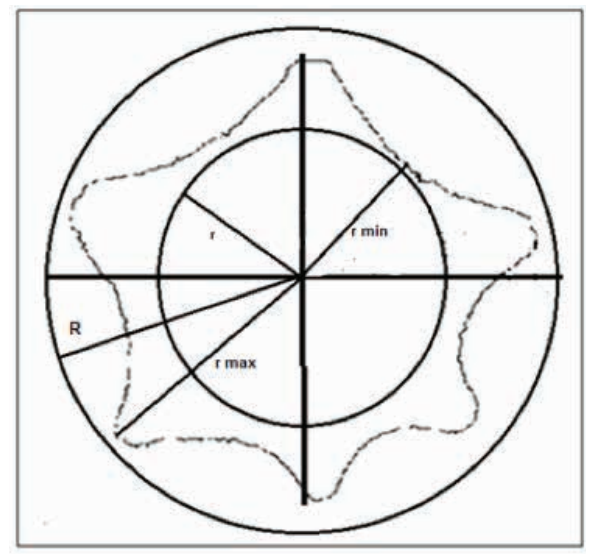

Figure 4. The various dimensions used in the calculation of drape distance ratio (DDR\%) and the folds depth index (FDI\%)

human knowledge. Fuzzy logic allows the modeling of data imperfections and is to some extent similar to the flexibility of human reasoning.

By introducing the notion of degree of belonging into the verification of a condition, we allow one condition to be in another state than true or false. Fuzzy logic thus confers considerable flexibility on the reasoning that uses it, which makes it possible to take into account inaccuracies and uncertainties. One of the interests of Fuzzy logic in formalizing human reasoning is that rules are stated in natural language.

By its numerical aspects, it is opposed to modal logics. It is based on the mathematical theory of fuzzy sets by Zadeh [22], which presents an extension of the theory of classical sets to sets defined imprecisely.

To evaluate the performance of the obtained Fuzzy logic models, three statistical performance criteria, including correlation coefficient $(R)$, mean absolute relative error (MARE), and root mean square error (RMSE), were used in this study. These parameters were calculated for testing $(T)$ and training (tr) phases:

$$
\begin{aligned}
& \text { RMSE }=\sqrt{\frac{\sum_{K=1}^{N}\left(y_{p-y_{k}}^{k}\right)^{2}}{N}} \\
& R=\sqrt{\left(1-\frac{\sum_{k=1}^{N}\left(y_{k}-y_{p}^{k 2}\right)}{\sum_{K=1}^{N}\left(y_{k}-\bar{y}_{k}^{2}\right)} ; \overline{y_{k}}\right.}=\frac{1}{N} \sum_{K=1}^{N} y_{k}
\end{aligned}
$$

$$
\text { MARE }=\frac{1}{N} \sum_{k=1}^{N}\left|\frac{y_{k-y_{p}^{k}}}{y_{k}}\right| \times 100
$$

In Equations (6), (7), and (8), $y^{k}{ }_{p}$ is the $k^{\text {th }}$ model predicted value, $y_{k}$ is the observed value corresponding to the inputs that give, $y_{k}$ is the mean of the observed values, and $N$ is the number of data points. It has to be noticed that a smaller RMSE means a better model accuracy, whereas a higher $R$ means the better the model performs in prediction.

\section{Results and discussions}

\subsection{Selection of inputs/outputs for the Fuzzy inference system}

The Fuzzy logic system has a class of inputs and an output class. In Table 2 the minimum average and maximum values of some properties of fabrics are presented to be taken as inputs in the system. The input parameters are divided into two classes: the mechanical parameters that are bending rigidity in the skew, warp, and weft directions and the shear rigidity. Also, there is the construction parameter that is the basis weight. Statistical summary of output variables such as DC, node number, DDR, and the FDI are presented in Table 3.

Table 2.Input variables

\begin{tabular}{|c|c|c|c|}
\hline Fabric parameters & Minimum & Average & Maximum \\
\hline$B_{\text {skew }}(\mathrm{cg} \cdot \mathrm{cm})$ & 0.081 & 4.421 & 8.761 \\
\hline$B_{\text {warp }}(\mathrm{cg} \cdot \mathrm{cm})$ & 0.186 & 3.518 & 6.850 \\
\hline$B_{\text {weft }}(\mathrm{cg} \cdot \mathrm{cm})$ & 0.072 & 7.538 & 15.010 \\
\hline$G(\mathrm{~N} / \mathrm{m})$ & 30.910 & 176.890 & 322.900 \\
\hline$W\left(\mathrm{~g} / \mathrm{m}^{2}\right)$ & 65 & 211 & 357 \\
\hline
\end{tabular}

In Table 4, the selected classes are three in number (low, medium, and high). The choice is made according to the following classification of results found by the Fuzzy-C-mean (FCM) method [23].

\subsection{Choice of membership functions}

This study section is devoted to the choice of the membership function for the different properties. It is conducted according to the results found in the Fuzzy classification made by Hamdi et al. [23]. The choice of interval data and the upper and lower limits of each class in every parameter are performed according to the results presented in Table 1.

\subsubsection{Membership function for input variables}

The membership functions for input variables are presented in Figure 5 . They are the bending rigidities, shear stiffness, and

Table 3. Output variables

\begin{tabular}{|c|c|c|c|}
\hline Drape parameters & Minimum & Average & Maximum \\
\hline Drape coefficient (DC) & 0.28 & 0.615 & 0.95 \\
\hline Node number (NN) & 2 & 6 & 10 \\
\hline Draped distance Ratio (DDR) & 0.89 & 0.495 & 0.1 \\
\hline Folds depth index (FDI) & 0.34 & 0.45 & 0.56 \\
\hline
\end{tabular}


Table 4. Membership class

\begin{tabular}{|c|c|c|c|}
\hline Variables & Class 1 & Class2 & Class3 \\
\hline$B_{\text {skew }}(\mathrm{cg} \cdot \mathrm{cm})$ & Low & Medium & High \\
\hline$B_{\text {warp }}(\mathrm{cg} \cdot \mathrm{cm})$ & Low & Medium & High \\
\hline$B_{\text {weft }}(\mathrm{cg} \cdot \mathrm{cm})$ & Low & Medium & High \\
\hline$G(\mathrm{~N} / \mathrm{m})$ & Low & Medium & High \\
\hline$W\left(\mathrm{~g} / \mathrm{m}^{2}\right)$ & Low & Medium & High \\
\hline Drape coefficient $(\mathrm{DC})$ & Low & Medium & High \\
\hline Node number $(\mathrm{NN})$ & High & Medium & Low \\
\hline $\begin{array}{c}\text { Draped distance Ratio } \\
(\mathrm{DDR})\end{array}$ & High & Medium & Low \\
\hline Folds depth Index (FDI) & Low & Medium & High \\
\hline
\end{tabular}

surface density. It is remarkable that the selected classes are three in number and that the shape used is trapezoidal. The coordinates of each main item belonging to a form with a specific class are presented in Table 1. We note that the presentation of the membership function of each class has its own specificity. In fact, the first class is characterized by three points: the first is the minimum experimental value and the level of the highest membership, the second point is the minimum experimental value of the second class, and the third point corresponds to the maximum experimental value in this class with a zero-affiliation degree. The second class is characterized by four points.
The first is the minimum experimental value in this class. The second is the maximum experimental value in the first class. The third point is the minimum experimental value in the third class and the fourth point is the maximum experimental value in the second class and having a zero-affiliation degree. Finally, the third class is characterized by three points. The first is the minimum experimental value in this class and has a degree equal to zero. The second point is the maximum experimental value in the second class and the third point represents the maximum value in the third class.

\subsubsection{Membership function for output variables}

In Figure 6, the membership function for output variables is presented through the DC, NN, DDR, and FDI. The same procedure is followed for the submission of membership functions as cited in the foregoing and according to the data mentioned in Table 4.

\subsection{List of rules used}

In Table 5, a list of rules linking the input and output variables is presented. Intuitively, it seems that the input variables as such are approximately appreciated by the brain, thus corresponding to the degree of verification of condition of Fuzzy logic. A comprehensive system of rules based on the Fuzzy logic helping to make decisions is called Fuzzy inference system. This list is based on the expertise of some industrialists, professionals, and researchers who are experts in the field of
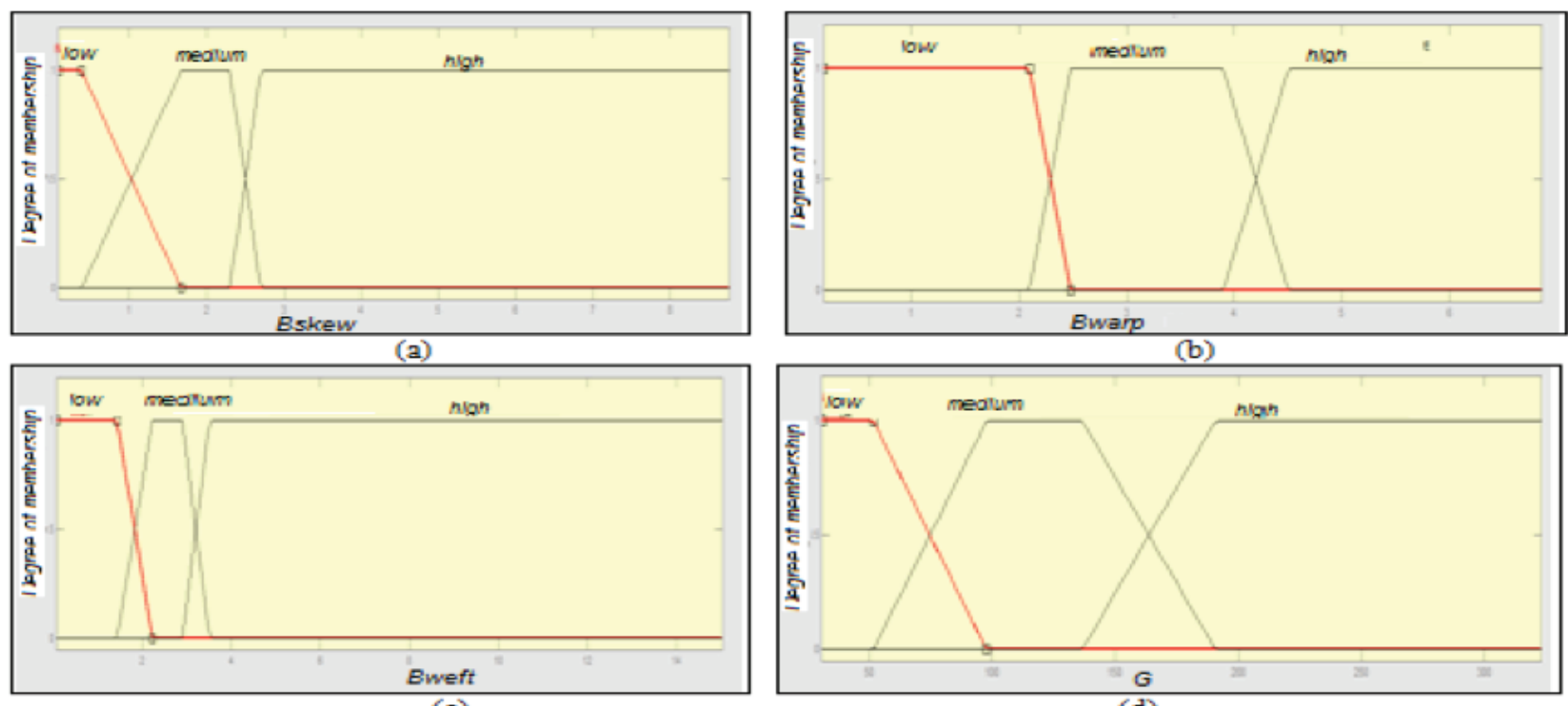

(c)

(d)

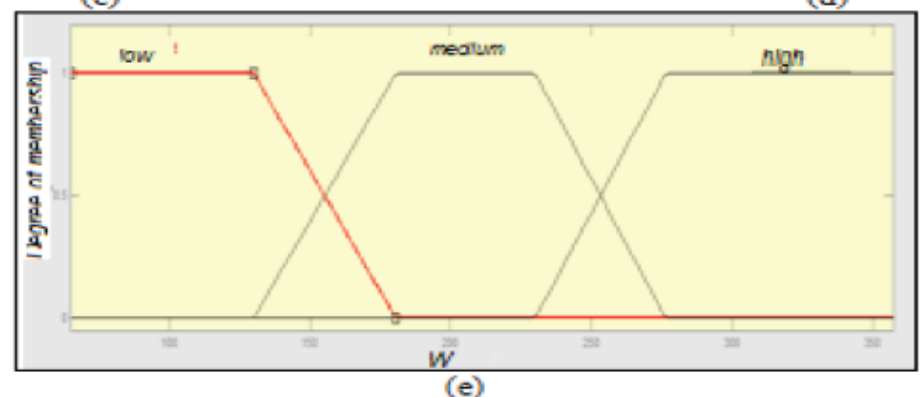

(e)

Figure 5. Membership function for input variables: (a) $B_{\text {skew' }}$ (b) $B_{\text {warp }}$, (c) $B_{\text {weft' }}$ (d) shear rigidity, and (e) surface mass 


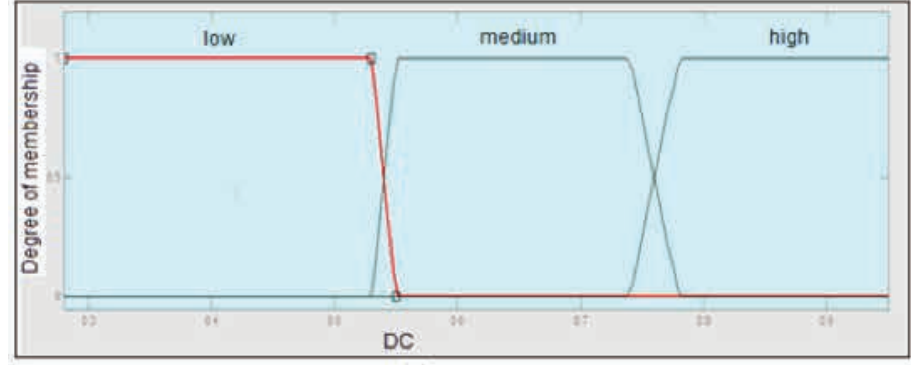

(a)

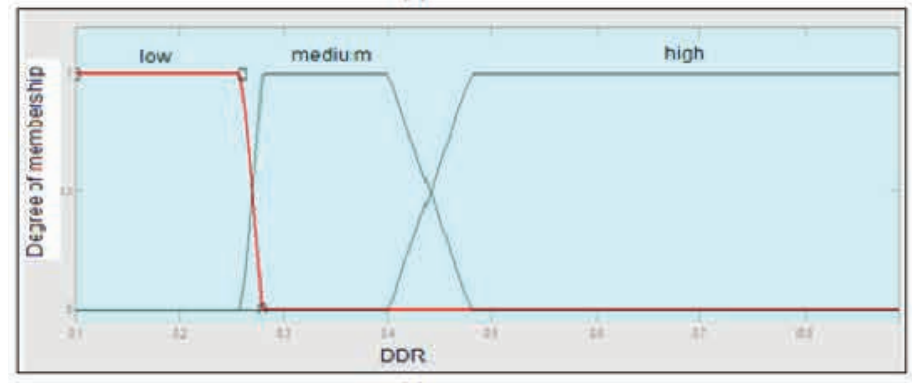

(c)

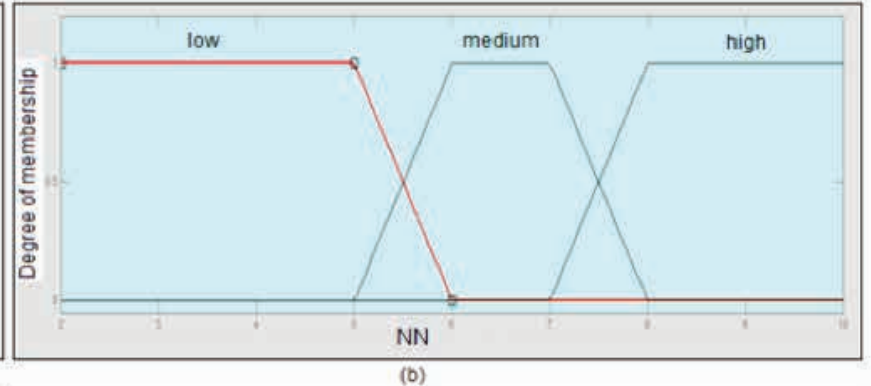

(b)

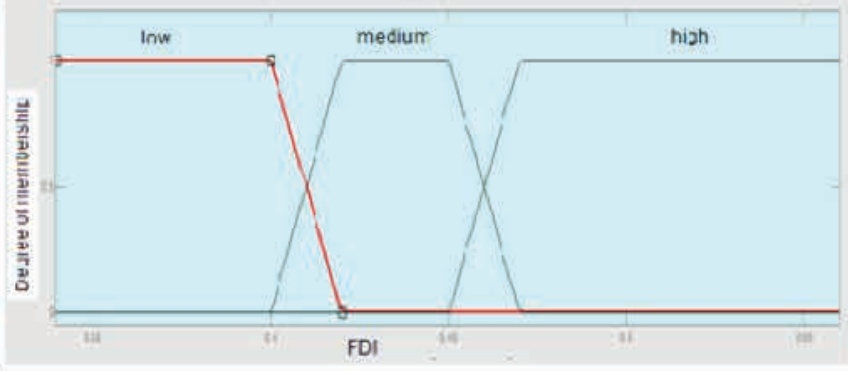

(d)

Figure 6. Membership function for output variables: (a) drape coefficient (DC), (b) number of node number (NN), (c) draped distance ratio (DDR), and (d) foldss depth index depth (FDI)

Table 5. List of rules

\begin{tabular}{|c|c|c|c|c|c|c|c|c|c|}
\hline $\begin{array}{c}\mathbf{N}^{\circ} \\
\text { rules }\end{array}$ & $\boldsymbol{B}_{\text {skew }}$ & $\boldsymbol{B}_{\text {warp }}$ & $\boldsymbol{B}_{\text {weft }}$ & $\boldsymbol{G}$ & $\boldsymbol{W}$ & DC & NN & DDR & FDI \\
\hline $\mathbf{1}$ & $\mathrm{H}$ & $\mathrm{H}$ & $\mathrm{H}$ & $\mathrm{H}$ & $\mathrm{H}$ & $\mathrm{H}$ & $\mathrm{L}$ & $\mathrm{L}$ & $\mathrm{H}$ \\
\hline $\mathbf{2}$ & $\mathrm{H}$ & $\mathrm{H}$ & $\mathrm{H}$ & $\mathrm{H}$ & $\mathrm{M}$ & $\mathrm{H}$ & $\mathrm{L}$ & $\mathrm{L}$ & $\mathrm{H}$ \\
\hline $\mathbf{3}$ & $\mathrm{H}$ & $\mathrm{H}$ & $\mathrm{H}$ & $\mathrm{M}$ & $\mathrm{H}$ & $\mathrm{H}$ & $\mathrm{L}$ & $\mathrm{L}$ & $\mathrm{H}$ \\
\hline $\mathbf{4}$ & $\mathrm{H}$ & $\mathrm{M}$ & $\mathrm{H}$ & $\mathrm{H}$ & $\mathrm{H}$ & $\mathrm{H}$ & $\mathrm{L}$ & $\mathrm{L}$ & $\mathrm{H}$ \\
\hline $\mathbf{5}$ & $\mathrm{H}$ & $\mathrm{M}$ & $\mathrm{M}$ & $\mathrm{M}$ & $\mathrm{M}$ & $\mathrm{M}$ & $\mathrm{M}$ & $\mathrm{M}$ & $\mathrm{M}$ \\
\hline $\mathbf{6}$ & $\mathrm{L}$ & $\mathrm{L}$ & $\mathrm{L}$ & $\mathrm{L}$ & $\mathrm{L}$ & $\mathrm{L}$ & $\mathrm{H}$ & $\mathrm{H}$ & $\mathrm{L}$ \\
\hline $\mathbf{7}$ & $\mathrm{L}$ & $\mathrm{L}$ & $\mathrm{L}$ & $\mathrm{L}$ & $\mathrm{M}$ & $\mathrm{L}$ & $\mathrm{H}$ & $\mathrm{H}$ & $\mathrm{L}$ \\
\hline $\mathbf{8}$ & $\mathrm{L}$ & $\mathrm{L}$ & $\mathrm{L}$ & $\mathrm{M}$ & $\mathrm{L}$ & $\mathrm{L}$ & $\mathrm{H}$ & $\mathrm{H}$ & $\mathrm{L}$ \\
\hline $\mathbf{9}$ & $\mathrm{L}$ & $\mathrm{L}$ & $\mathrm{L}$ & $\mathrm{M}$ & $\mathrm{M}$ & $\mathrm{L}$ & $\mathrm{H}$ & $\mathrm{H}$ & $\mathrm{L}$ \\
\hline $\mathbf{1 0}$ & $\mathrm{L}$ & $\mathrm{M}$ & $\mathrm{M}$ & $\mathrm{L}$ & $\mathrm{M}$ & $\mathrm{M}$ & $\mathrm{M}$ & $\mathrm{M}$ & $\mathrm{M}$ \\
\hline $\mathbf{1 1}$ & $\mathrm{L}$ & $\mathrm{M}$ & $\mathrm{M}$ & $\mathrm{M}$ & $\mathrm{M}$ & $\mathrm{M}$ & $\mathrm{M}$ & $\mathrm{M}$ & $\mathrm{M}$ \\
\hline $\mathbf{1 2}$ & $\mathrm{M}$ & $\mathrm{H}$ & $\mathrm{H}$ & $\mathrm{H}$ & $\mathrm{M}$ & $\mathrm{M}$ & $\mathrm{M}$ & $\mathrm{M}$ & $\mathrm{M}$ \\
\hline $\mathbf{1 3}$ & $\mathrm{M}$ & $\mathrm{L}$ & $\mathrm{L}$ & $\mathrm{L}$ & $\mathrm{M}$ & $\mathrm{L}$ & $\mathrm{H}$ & $\mathrm{H}$ & $\mathrm{L}$ \\
\hline $\mathbf{1 4}$ & $\mathrm{M}$ & $\mathrm{L}$ & $\mathrm{L}$ & $\mathrm{M}$ & $\mathrm{M}$ & $\mathrm{L}$ & $\mathrm{M}$ & $\mathrm{M}$ & $\mathrm{L}$ \\
\hline $\mathbf{1 5}$ & $\mathrm{M}$ & $\mathrm{M}$ & $\mathrm{L}$ & $\mathrm{M}$ & $\mathrm{H}$ & $\mathrm{M}$ & $\mathrm{M}$ & $\mathrm{M}$ & $\mathrm{M}$ \\
\hline $\mathbf{1 6}$ & $\mathrm{M}$ & $\mathrm{M}$ & $\mathrm{L}$ & $\mathrm{M}$ & $\mathrm{L}$ & $\mathrm{M}$ & $\mathrm{M}$ & $\mathrm{M}$ & $\mathrm{M}$ \\
\hline $\mathbf{1 7}$ & $\mathrm{M}$ & $\mathrm{M}$ & $\mathrm{L}$ & $\mathrm{M}$ & $\mathrm{M}$ & $\mathrm{L}$ & $\mathrm{H}$ & $\mathrm{H}$ & $\mathrm{L}$ \\
\hline $\mathbf{1 8}$ & $\mathrm{M}$ & $\mathrm{M}$ & $\mathrm{M}$ & $\mathrm{H}$ & $\mathrm{M}$ & $\mathrm{M}$ & $\mathrm{M}$ & $\mathrm{M}$ & $\mathrm{M}$ \\
\hline $\mathbf{1 9}$ & $\mathrm{M}$ & $\mathrm{M}$ & $\mathrm{M}$ & $\mathrm{L}$ & $\mathrm{L}$ & $\mathrm{L}$ & $\mathrm{H}$ & $\mathrm{H}$ & $\mathrm{L}$ \\
\hline $\mathbf{2 0}$ & $\mathrm{M}$ & $\mathrm{M}$ & $\mathrm{M}$ & $\mathrm{L}$ & $\mathrm{M}$ & $\mathrm{M}$ & $\mathrm{M}$ & $\mathrm{M}$ & $\mathrm{M}$ \\
\hline $\mathbf{2 1}$ & $\mathrm{M}$ & $\mathrm{M}$ & $\mathrm{M}$ & $\mathrm{M}$ & $\mathrm{H}$ & $\mathrm{M}$ & $\mathrm{M}$ & $\mathrm{M}$ & $\mathrm{M}$ \\
\hline $\mathbf{2 2}$ & $\mathrm{M}$ & $\mathrm{M}$ & $\mathrm{M}$ & $\mathrm{M}$ & $\mathrm{L}$ & $\mathrm{M}$ & $\mathrm{M}$ & $\mathrm{M}$ & $\mathrm{M}$ \\
\hline $\mathbf{2 3}$ & $\mathrm{M}$ & $\mathrm{M}$ & $\mathrm{M}$ & $\mathrm{M}$ & $\mathrm{M}$ & $\mathrm{M}$ & $\mathrm{M}$ & $\mathrm{M}$ & $\mathrm{M}$ \\
\hline
\end{tabular}

DC, drape coefficient; NN, node number; DDR, drape distance ratio; FDI, folds depth index. textile and clothing and the experimental tests performed in this work. In this table, the following codes are used:

"L": This code stands for the term "Low."

"M": This code stands for the term "Medium."

“"'H"': This code stands for the term "“'High."”

\subsection{General structure of the Fuzzy system}

The executed Fuzzy calculation system is characterized by the following parameters:

The type of Fuzzy system = 'Mamdani' .

Number of inputs $=5$.

Number of outputs $=4$.

Rules number $=23$.

The method used in the procedure is "And" = 'min'.

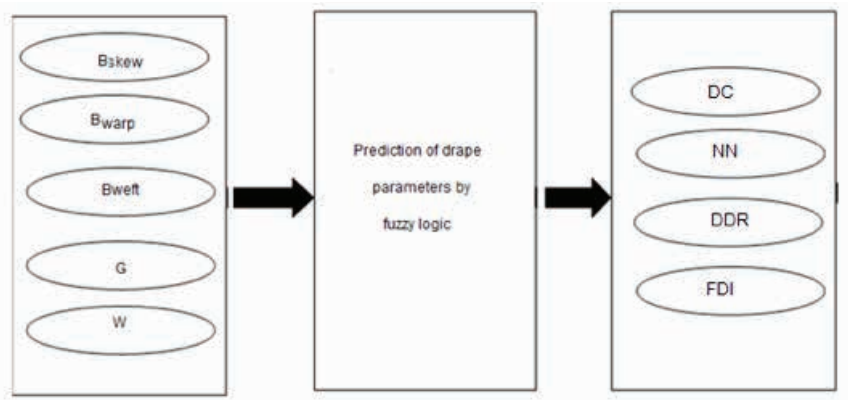

Figure 7. The general structure of fuzzy system 


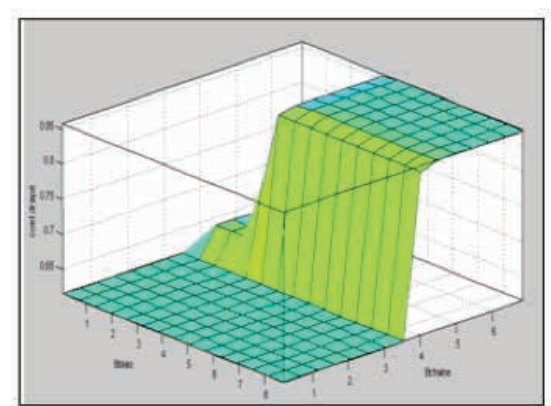

(a)
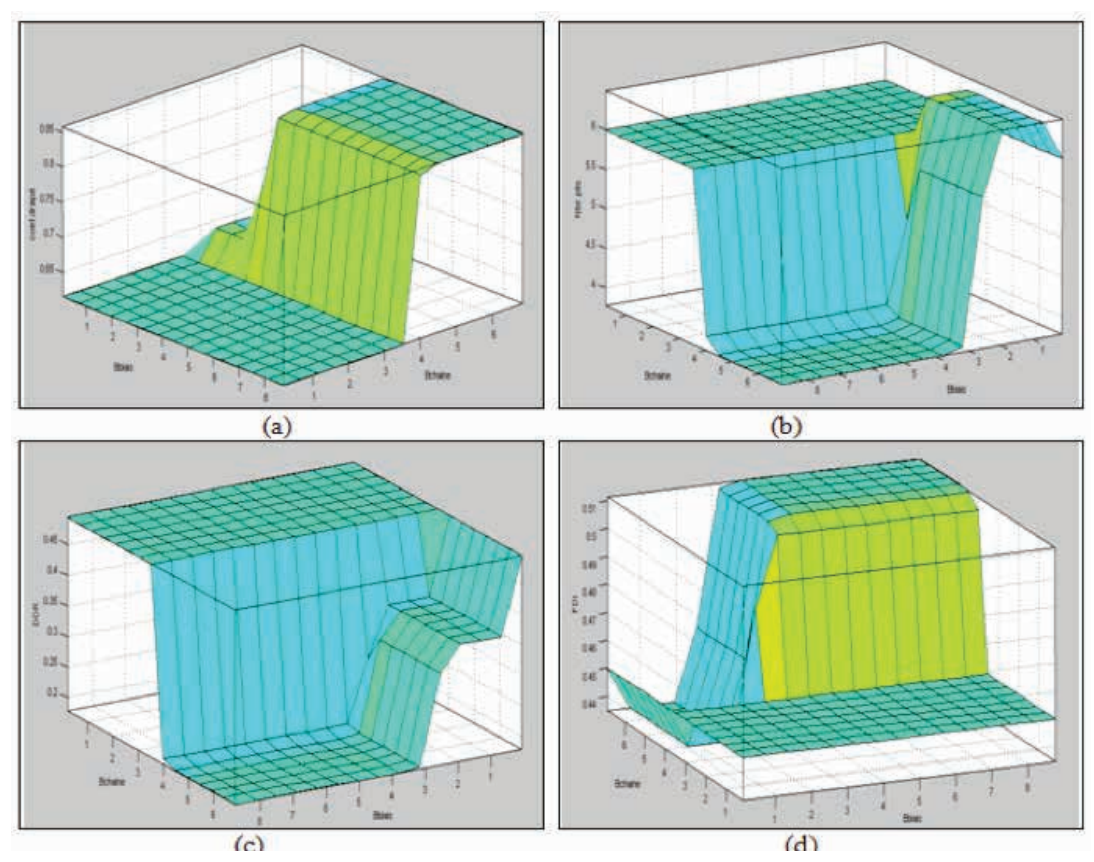

Figure 8. The Fuzzy surfaces responses from drape parameters according to bending rigidities in the skew and warp direction

The method used in the procedure is "Or" = 'max'.

The method used in the phase is fuzzification = 'centroid'.

Figure 7 shows the general structure of the fuzzy system.

\subsection{Fuzzy response surfaces}

Fuzzy logic is a method based on the principle of membership degrees. In this context and depending on the rules that link inputs and outputs to the membership of each property of functions with upper and lower limits of each class and each variable, one can draw the evolution of each output depending on the selected inputs. Figure 8 presents the Fuzzy response surfaces of variations of drape parameters according to the bending rigidities in the warp and skew directions.

According to Figure 7 , we can conclude that DC increases with $B_{\text {skew }}$ and $B_{\text {warp }}$. The number of node increases when $B_{\text {skew }}$ and $B_{\text {warp }}$ decreases. The DDR increases when $B_{\text {skew }}$ and $B_{\text {warp }}$ decreases. The FDI increases with $B_{\text {skew }}$ and $B_{\text {warp }}$.

\subsection{Evaluating the results of calculating drape parameters}

To validate the results found by the realized computing system, conducting a test step is necessary. Figure 9 shows the correlation between the experimental values and the values calculated by the Fuzzy system. This analysis is performed to evaluate the effectiveness and reliability of the method based on Fuzzy logic of calculating drape parameters (DC, NN, DDR, and FDI).

Throughout this figure, a high correlation values appears. Indeed, the correlation coefficient values of DC, NN, DDR, and FDI are as follows: $R_{\mathrm{DC}}=0.943, R_{\mathrm{NN}}=0.936, R_{\mathrm{DDR}}=0.969$, and $R_{\mathrm{FDI}}=0.946$. From these results, it is possible to conclude that the computing system is considered as efficient to a great extent and that it has reached a success rate. At the same time
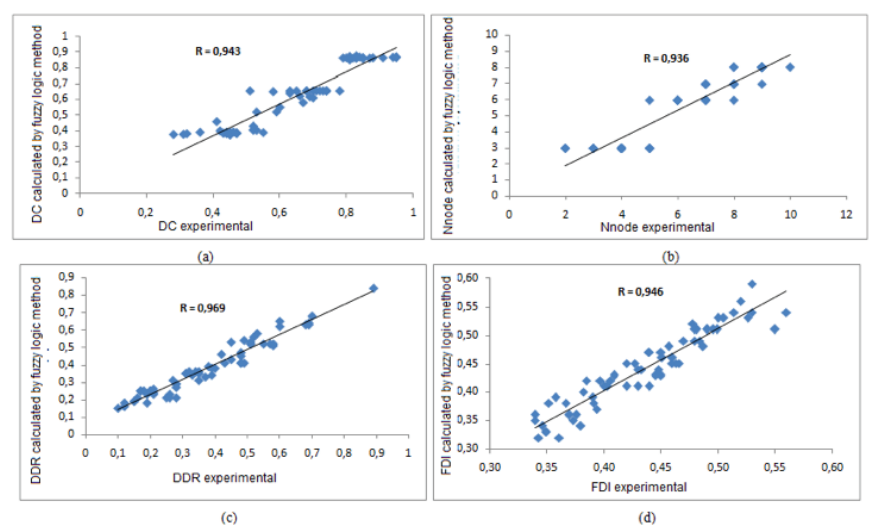

Figure 9. The correlation between the experimental values of drape parameters and those calculated by the Ffuzzy system: (a) drape coefficient (DC), (b) number of node number (NN), (c) drape distance ratio (DDR), and (d) folds depth index (FDI).

Table 6. Performance of Fuzzy logic method for predicting drape parameters

\begin{tabular}{|c|c|c|c|c|}
\hline \multicolumn{2}{|c|}{} & \multicolumn{3}{|c|}{ Variables of performance } \\
\hline Characteristics & $\begin{array}{c}\text { Standard } \\
\text { deviation }\end{array}$ & RMSE & MARE & R \\
\hline DC & 0.181 & 0.069 & 0.108 & 0.943 \\
\hline NN & 2.190 & 0.755 & 0.130 & 0.936 \\
\hline DDR & 0.174 & 0.044 & 0.138 & 0.969 \\
\hline FDI & 0.058 & 0.022 & 0.046 & 0.946 \\
\hline
\end{tabular}

and according to Table 6, the values of the average of the root mean square error (RMSE) obtained are acceptable because they are less compared to the standard deviation, which proves the acceptance limit of this error for all the characteristics of drape studied. In the footsteps of what has just been mentioned, the mean absolute relative errors (MARE) are very low. From these results, we can conclude that our computing system is considered representative and significant. 


\section{Conclusions}

The fuzzy logic method described for the prediction of drape parameters has been found efficient for proving all drape properties at the same time, which indicates a high correlation between theoretical and experimental values $\left(R_{\mathrm{CD}}=0.943, R_{\mathrm{NN}}\right.$ $=0.936, R_{\mathrm{DDR}}=0.969$, and $\left.R_{\mathrm{FDI}}=0.946\right)$. It further implies that the Fuzzy logic model is feasible for the prediction of fabric drape from the values of fabric bending rigidity in 3three directions (warp, weft, and skew direction), shear rigidity, and fabric surface mass.

\section{Acknowledgments}

This research was funded by the Deanship of Scientific Research at Princess Nourah bint Abdulrahman University through the Fast-track Research Funding Program

\section{References}

[1] Basu, A., Chellamani, K. P., Ramesh, P. R. (2002). Fabric engineering by means of an artificial neural network. Journal of the Textile Institute, 93(3), 283-296.

[2] Hu, J. L., Chan, Y. F. (1998). Effect of fabric mechanical properties on drape. Textile Research Journal, 68 (1), 5764.

[3] Tehran, M. A., Maleki, M. (2011). Artificial neural network prosperities in textile applications, Croatia: InTech, Rijeka, pp. 35-64.

[4] Fan, J., Newton, E., Au, R., Chan, S. (2001). Predicting garment drape with fuzzy neural network. Textile Research Journal, 71(7), 605-608.

[5] Guo, Z. X., Wong, W. K., Leung, S. Y. S., Li, M. (2011). Applications of artificial intelligence in the apparel industry. Textile Research Journal, 81(18), 1871-1892.

[6] Guruprasad, R., Behera, B. K. (2010). Soft computing in textiles. Indian Journal of Fibre and Textile Research, 35(1), 75-84.

[7] Vassiliadis, S., Rangoussi, M., Cay, A., Provatidis, C. (2010). Woven fabric engineering: artificial neural networks and their applications in the engineering of fabrics. Croatia: Sciyo, Rijeka, pp. 112-134.

[8] Chattopadhyay, R., Guha, A. (2004). Artificial neural networks: applications to textiles. Textile Progress, 35(1), $1-46$.
[9] Breen, D. E., House, D. H., Wozny, M. J. (1994). A particlebased model for simulating the draping behavior of woven cloth. Textile Research Journal, 64(11), 663-685.

[10] Pattanayak, A. K., Ameersing, L., Asimananda, K. (2010). Prediction of drape profile of cotton woven fabrics using artificial neural network and multiple regression method. Textile Research Journal, 81(6), 559-566.

[11] Chu, C. C., Cumming, C. L., Teixeira, N. A. (1950). Mechanic $s$ of elastic performance of textile materials. Textile Research Journal, 20(8), 539-548.

[12] Cusick, G. E. (1965). The dependence of fabric drape on bending and shearing stiffness. Journal of the Textile Institute, 65(5), 596-606.

[13] Mooreka, H., Niwa, M. (1976). Relation between drape coefficient and mechanical properties of fabric. Journal of Textile Institute, 22(3), 63-67.

[14] Ayada, M., Niwa, M. (1991). Relation between the comfort of gathered skirts and fabric mechanical properties. Sen-I Gakkaaishi, 47(6), 291-298.

[15] Bruniaux, P., Vasseur, C. (2001). Modeling and identifying the parameters of a fabric drape model. Textile Research Journal, 71(4), 336-342

[16] Bruniaux,P., Ghith, A., Vasseur, C. (2003). Modelling and parametric study of a fabric drape. Advances in Complex Systems, 6(4), 457-476.

[17] Ghith, A., Hamdi, T., Fayala, F. (2015). Prediction of drape coefficient by artificial neural network. Autex Research Journal, 15(4), 266-274.

[18] Hamdi, T., Ghith, A., Fayala, F. (2014). A principal component analysis method for predicting the correlation between some fabric parameters and the drape. AUTEX Research Journal, 14(1), 22-27.

[19] AFNOR (1984). Essais des étoffes, Détermination de la masse surfacique des tissus et des tricots. Normes Françaises; NF G 07-150.

[20] Hamdi, T., Ghith, A., Fayala, F. (2013). Study of drape parameter using image analysis. International Journal of Engineering Science and Technology, 5(7), 1456-1464.

[21] Jeong, Y.J., Philips, D.G. (1998). A study of fabric-drape behavior with image analysis part I: Measurement, characterization, and instability. Journal of the Textile Institute, 88(1), 59-69.

[22] Zadeh, L. A. (1965). Fuzzy sets. Information and Control, 8(3), 338-353.

[23] Hamdi, T., Ghith, A., Fayala, F. (2017). Characterization of drape profile using Fuzzy-C-mean (FCM) method. Fibers and Polymers Journal, 18(7), 1401-1407. 